\title{
SPINAL DYSRAPHISM; FREQUENCY OF RARE CASES OF SPINAL DYSMORPHISM IN VIEW OF MRI FINDINGS
}

\section{Dr. Bushra Ujala1, Dr. Saeeda Bano², Dr. Asma Mehreen ${ }^{3}$, Dr. Hassan Bukhari ${ }^{4}$}

1. Assistant Professor Radiology Allied Hospital Faisalabad.

2. Assistant Professor Obs / Gynea SLMC Sahiwal.

3. Fellow of Pediatric Hematology / Oncology SKMH Lahore.

4. Senior Registrar Radiology Allied Hospital Faisalabad.

Correspondence Address: Dr. Bushra Ujala Assistant Professor

Radiology Allied Hospital Faisalabad. Alhuda School, Hospital Road Dijkot, District Faisalabad.

bushra_ujala@yahoo.com

Article received on: 21/11/2016

Accepted for publication: 20/02/2017

Received after proof reading:

06/04/2017

\begin{abstract}
Introduction: MRI plays an important role in characterising spinal dysraphisms. The reason behind this is quality of MRI showing very high contrast resolution of soft tissues and the ability to detect fat in the lesion.T2 weighted images provide excellent contrast between the sub-arachnoid spaces and neural tissue while evaluating spinal dysraphisms. Objectives: To determine the frequency of rare disorders of spinal dysraphism in view of MRI findings of spinal dyspharism patients. Study Design: retrospective. Duration: the study was conducted from $1^{\text {st }}$ September 2015 to $30^{\text {th }}$ November 2015. Settings: Radiology department, Allied hospital Faisalabad. Methods: A total of 20 consecutive pediatric age group patients presented with clinical suspicion of spinal dysraphism were included. MRI L/S spine was carried out on 1.5Tesla Philips and diagnosis of various disorders of spinal dysraphism was made. Conclusion: MRI is the first choice examination for the detection of occult spinal dysraphism. Its timely diagnosis improving surgical \& medical outcome as well as better \& long term care of patients with spinal dysraphism. Majority of patients in the current study had tethered cord $(75 \%)$, myelomeningocele $(20 \%)$, myelocele $(10 \%)$, lipomyelocele $(10 \%)$ Dermal sinus tract $(10 \%)$ \& diastematomyelia (10\%) followed by associated spinal lipomas (5\%), caudal agenesis (5\%) \& anterior meningocele (5\%).
\end{abstract}

Key words: $\quad$ Spinal, dysraphism, MRI, tethered cord, myelomeningocele, diastematomyelia.

Article Citation: Ujala B, Bano S, Mehreen A, Bukhari H. Spinal dysraphism; Frequency of rare cases of spinal dysmorphism in view of MRI findings. Professional Med $\mathrm{J}$ 2017;24(4):565-573. DOI: 10.17957/TPMJ/17.3787

\section{INTRODUCTION}

Spinal dysraphism is an umbrella term that depicts any irregularity of the spinal cord, cauda equina or overlying tissues, for example, vertebrae, muscles and skin. The sensory system variation from the norm might have related mesenchymal or dermal changes..$^{1,2,3}$

It is a standout amongst the most well-known innate issue connected with noteworthy dreariness and mortality with evaluated rate of around 0.05 to 0.25 for every 1000 births ${ }^{4}$ Spinal dysraphisms can be comprehensively classified into open and cosed types. ${ }^{5,6}$ Open dysraphism, in which there is introduction of irregular sensory tissues through a skin imperfection, and close dysraphism, in which skin covers completely and in a continuous manner to the underlying spinal abnormality. ${ }^{5}$

Open spinal dysraphisms fundamentally incorporate myelomeningocele and other uncommon variations from the norm, for example, myelocele and hemimyelo (meningo) cele.

Close spinal dysraphisms are further sorted in view of the relationship with low-back subcutaneous masses. Close spinal dysraphisms with mass are shown by lipomyelocele, lipomyelomeningocele, meningocele, and myelocystocele. Close spinal dysraphisms withoutmass include basic dysraphic states (tight filumterminale, filar and intradural lipomas, persistent terminal ventricle, and dermal sinuses) and complex dysraphic states. The last class additionally contains deformities of midline notochordal combination (essentially represented by diastematomyelia) and defects of segmental notochordal arrangement (represented by caudal agenesis and spinal segmental dysgenesis). ${ }^{4}$

Magnetic resonance imaging is considered the investigation of choice for imaging the whole 
anatomy of the pediatric spine. Ultrasound can be used as a valuable screening method before ossification of the posterior elements of the spine, however there is still need for MRI imaging in cases, either of abnormal sonogram or babies with a normal ultrasound but having an associated neurological abnormality. ${ }^{9}$

Most of the patients in one review by Sury MR et al. (around $70 \%$ ) require sedation or a general anaesthesia. ${ }^{7,8}$

This study was conducted for the determination of the frequency of dysraphic states in our population as only a handful of studies have been conducted to date on this subject in our country. The advancement of newer radiological modalities, specifically multiplanar MRI, are progressively asked for in kids with known congenital scoliosis associated with spinal dysraphism and acquired causes for scoliosis, as it permits prevalent outline of the spinal segment without the radiation hazard. It will outline the sort and degree of dysraphism in kids. By knowing the commonest type we will make awareness in our population about its risk factors thereby making better and fast treatment possible and opening pathways for aggressive and more targeted treatment like timingly spinal surgery, thus improving surgical \& medical outcome as well as better \& long term care of patients with spinal dysraphism, hence preventing morbidity in these patients, as in the developed countries.

\section{AIM / OBJECTIVE}

To determine the frequency of rare disorders of spinal dysraphism in view of MRI findings of these patients.

\section{MATERIALS AND METHODS}

This study was retrospectively done at Radiology department Allied Hospital Faisalabad for a period of 3 months from $1^{\text {st }}$ September 2015 to $30^{\text {th }}$ November 2015. Clinical and radiological discoveries of 20 cases suspected as spinal dysraphism were contemplated and recognized distinctive range of dysraphism and arranged them. Pertinent history age, sex, birth history, formative history, presenting complaints and radiological types were recorded.
Inclusion criteria were all patients of pediatric age groups ranging from $1^{\text {st }}$ day of life to 10 years having $\mathrm{H} / \mathrm{o}$ swelling lumbosacral region, delayed milestones, urinary incontinence, hairy tuft lower back, weakness lower limbs, scoliotic deformity of spine.

Exclusion criteria were dysraphism in elder age groups \& Pts who refused to undergo study.

The MR imaging was done with 1.5T Siemens and image acquisition was made. Acquisition of high-quality diagnostic images is among the major challenges of the pediatric neuroimaging, as there is requirement for the infant or child to keep motionless during scanning.

The MRI protocols included: T1W images (500$600 / 10$ repetition time $\mathrm{ms} /$ echo time $\mathrm{ms}$ ) and T2W fast spin echo images (3000/100), obtained in the axial \& sagittal planes. Coronal planes were obtained in cases showing scoliosis. Section thickness was $3-4 \mathrm{~mm}$, an intersection gap was $1 \mathrm{~mm}$, field of view (FOV) of $250 \mathrm{~mm}$ and a flip angle of $90^{\circ}$. T1 and T2- weighted images were assessed for the evaluation of the lesion. Data collected through the specified proforma was analyzed on SPSS version 17.

\section{RESULTS}

A total of 20 patients including 11 females and 9 males were analyzed in the Department of Radiology, Allied Hospital Faisalabad from September 2015 to November 2015. A total of 17 (85\%) patients including 9(52.9\%) females and $8(47 \%)$ males with age range from $1^{\text {st }}$ day of life to 10 years were diagnosed as having spinal dysraphism with its associated manifestations. These cases were subsequently confirmed through open surgery, proving $100 \%$ sensitivity of the magnetic resonance imaging in diagnosing the spinal dysraphic states. Among these 17 patients, myelocele was found in 2, myelomeningocele was seen among 4 patients, lipomyelomeningocele was present in 2 cases, 1 case was of lipomyeloschisis, 1 case was of caudal agenesis. 2 cases were of diastematomyelia. 2 were having dorsal dermal sinus and 1 with filar lipoma. Anterior spinal defect 
and intradural lipomas were seen in 1 case each. The clinicoradiological findings in these cases are summarized in Table-l.

\begin{tabular}{|l|c|c|}
\hline \multicolumn{1}{|c|}{ Type } & $\begin{array}{c}\text { Case } \\
\text { Numbers }\end{array}$ & $\begin{array}{c}\text { Frequency } \\
\text { (\%) }\end{array}$ \\
\hline Myelocele & 2 & 10 \\
\hline Myelomeningocele & 4 & 20 \\
\hline Lipomyelomeningocele & 2 & 10 \\
\hline Lipomyeloschisis & 1 & 05 \\
\hline Caudal agenesis & 1 & 05 \\
\hline Diastematomyelia & 2 & 10 \\
\hline Dorsal dermal sinus & 2 & 10 \\
\hline Filar lipoma & 1 & 05 \\
\hline Intradural lipoma & 1 & 05 \\
\hline Anterior spinal defect & 1 & 05 \\
\hline Associated tethered cord & 15 & 75 \\
\hline and syrinx formation & Table-I & \\
\hline
\end{tabular}

\section{DISCUSSION}

Spinal dysraphism incorporates a range of inborn error, resulting from incomplete or abnormal closure of neural tube, while early embryogenesis is taking place.

Accordingly, fusion of spinal components in the midline either cannot take place or is incomplete. Spinal canal defects range from mild, asymptomatic lesions, e.g. spina bifida occulta (a small benign looking, bony cleft involving the $5^{\text {th }}$ lumbar vertebra or spinous process of the $1^{\text {st }}$ sacral vertebra) to serious defects of spinal elements, e.g, the meningomyelocele (an open neural tube defect). ${ }^{10}$

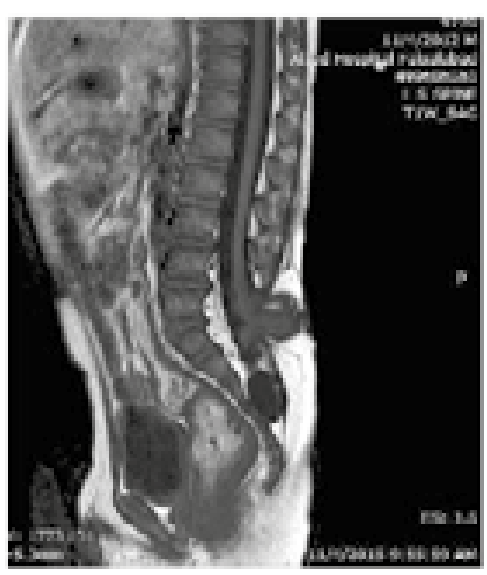

A

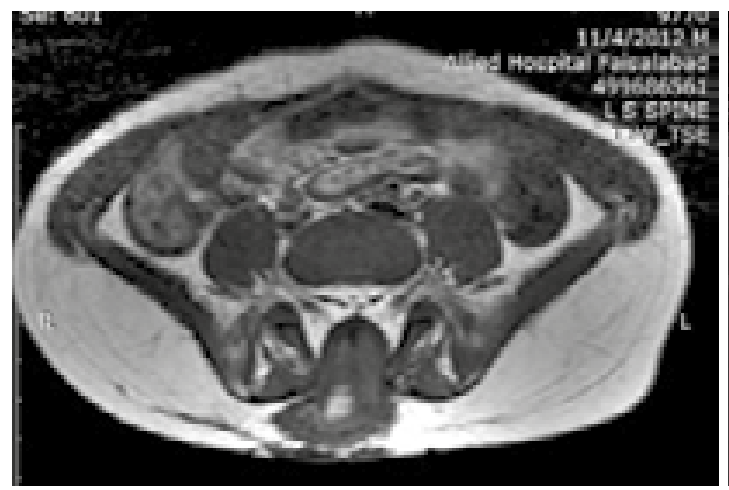

C

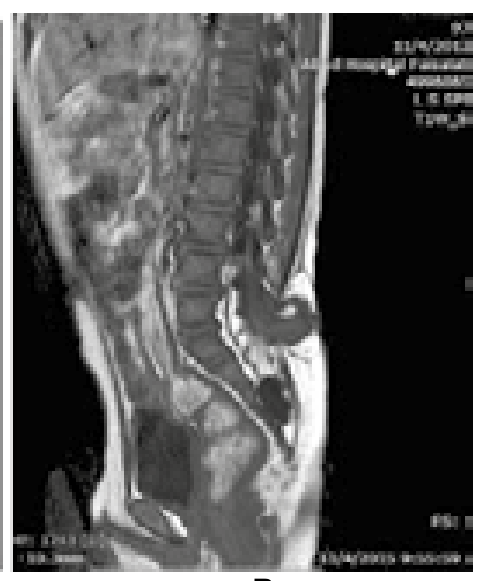

B

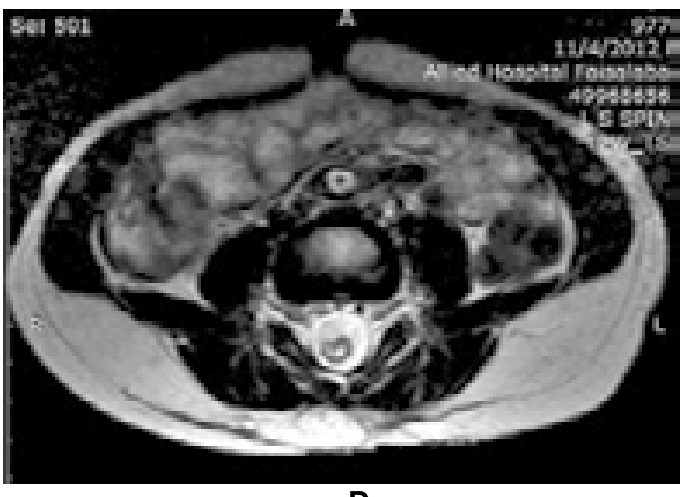

D

Figure-1. Myelomeningocele in a 3 year old male baby with swelling on back since birth.

T1W sagittal and axial MRI images ( $a, b, c)$ showing myelomeningocele, along with intraspinal lipoma. T2W axial (d) at higher level showing associated syrinx formation. 

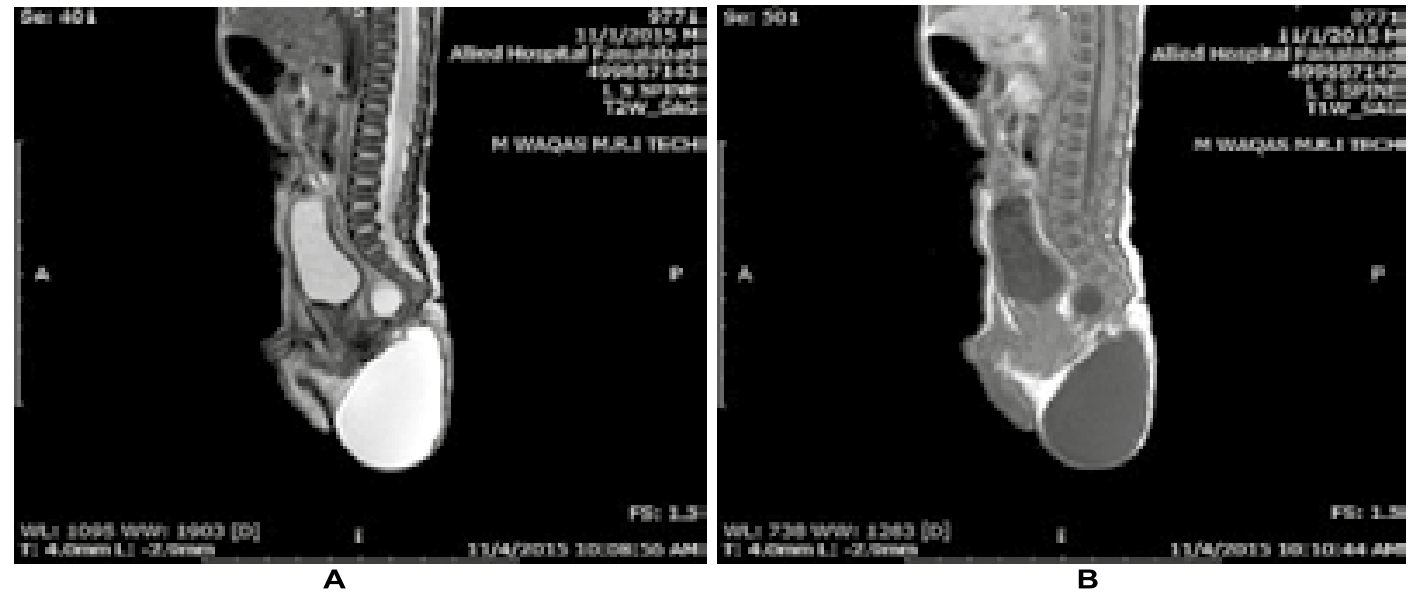

Figure-2. Caudal agenesis with meningocele in a 3 days old male infant.

MRI T2WI (a) \& T1W (b) sagittal images of the lumbosacral spine, showing caudal agenesis, sacral meningocele and associated tethered cord.

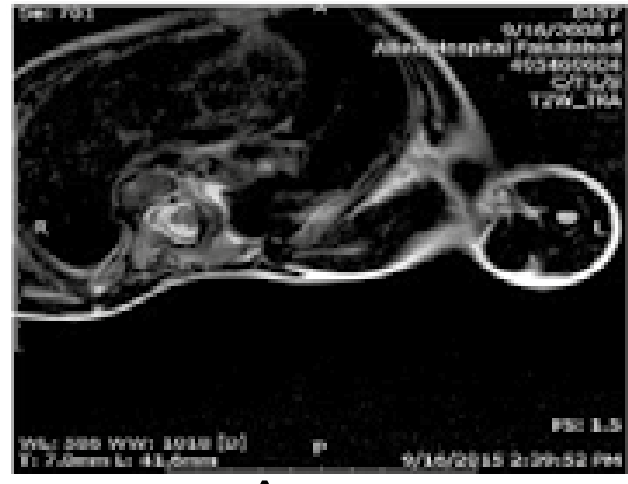

A

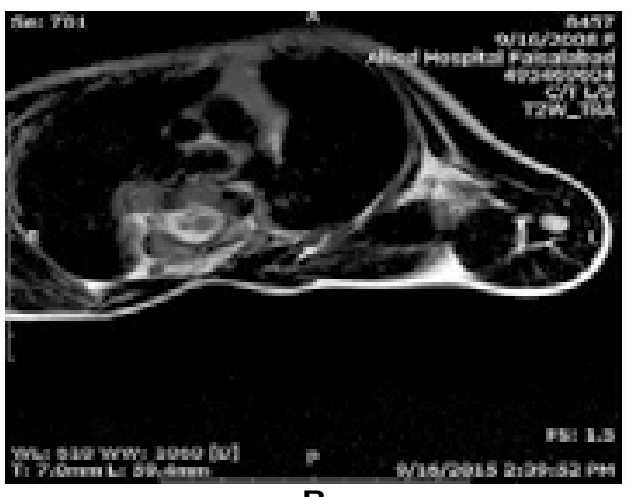

B

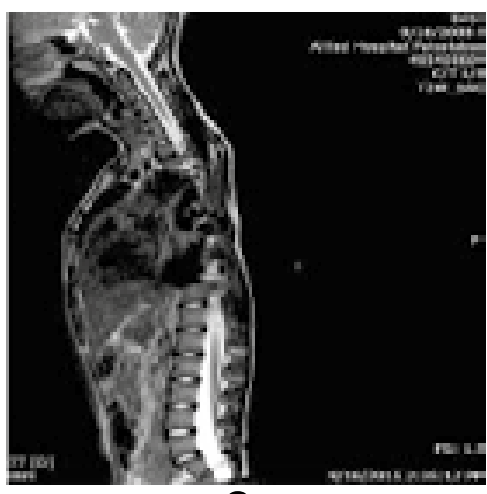

C

Figure-3. Diastematomyelia in a 7 year old girl with scoliotic deformity.

MRI T2W axial $(a, b)$ \& sagittal (c) images of the dorsal spine showing split hemicords, suggestive of diastematomyelia. Associated scoliotic deformity and tethered cord are also appreciated.

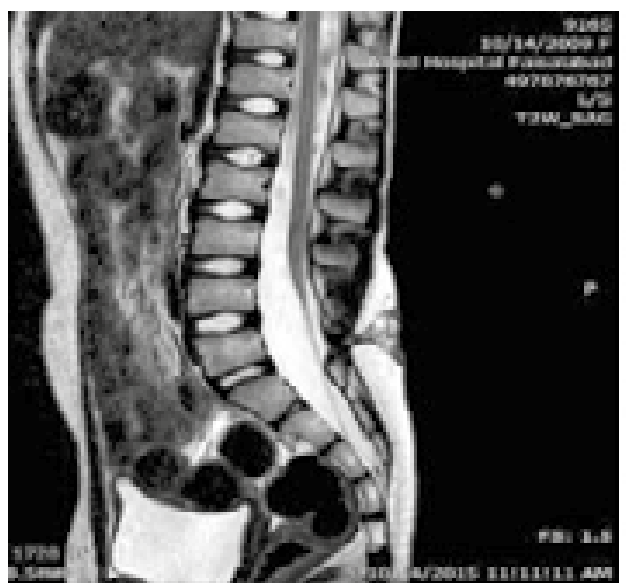

A

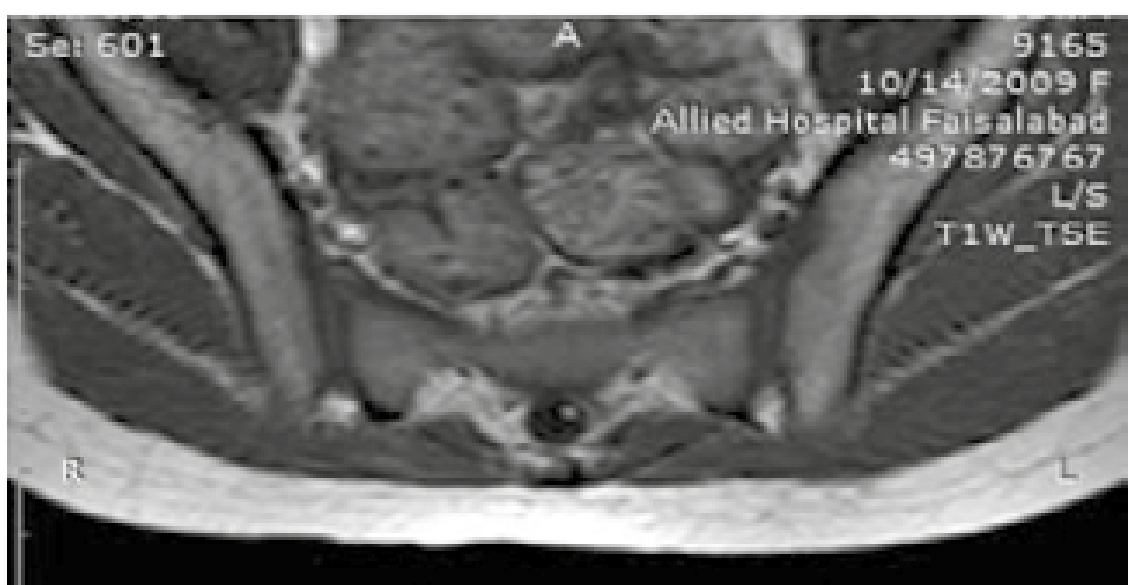

B

Figure-4. Dorsal dermal sinus in a 6 years old girl.

MRI T2W sagittal (a) showing dorsal dermal sinus \& tethered cord. Associated syrinx also appreciated. T1W axial image (b) showing associated filar lipoma as hyperintence T1W signal. 

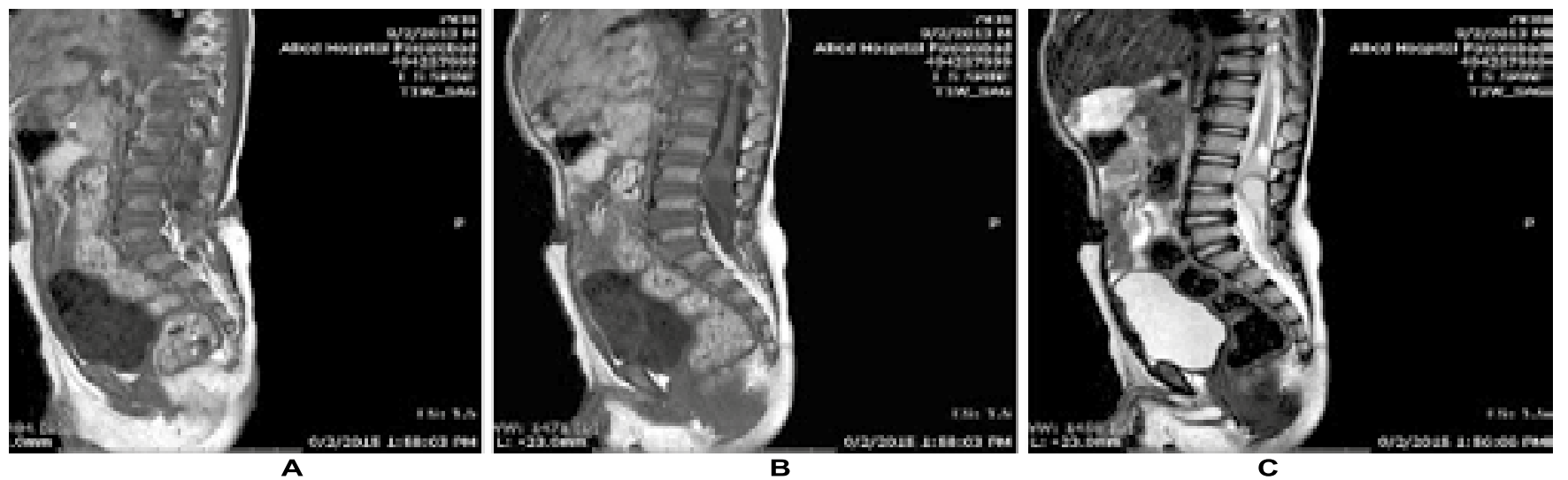

Figure-5. Dorsal dermal sinus with myelocystocele in a 2 years old male baby.

MRI T1W (a,b) \& T2W (c) sagittal images showing dorsal dermal sinus with tethered cord.

Note cystic dilatation of caudal central canal-myelocystocele.

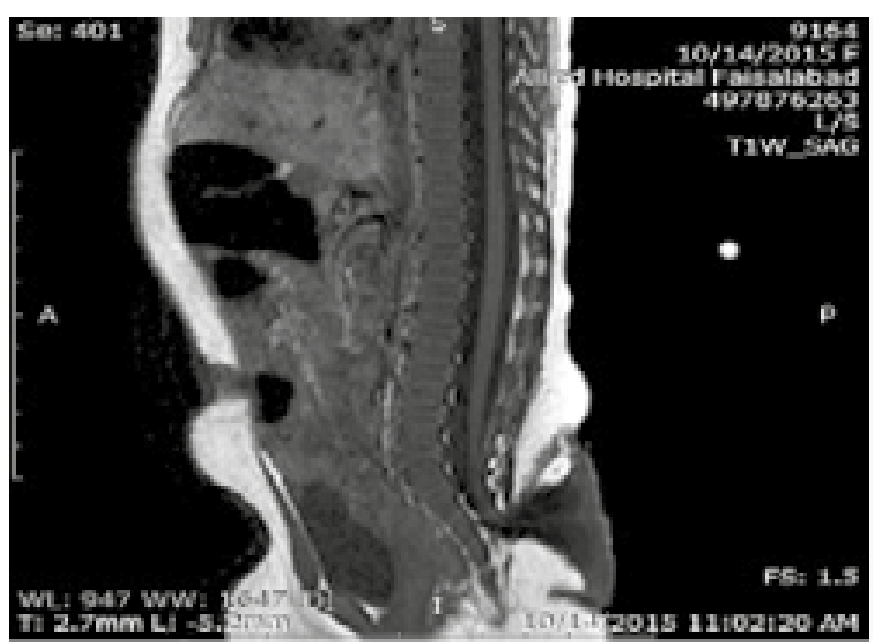

A

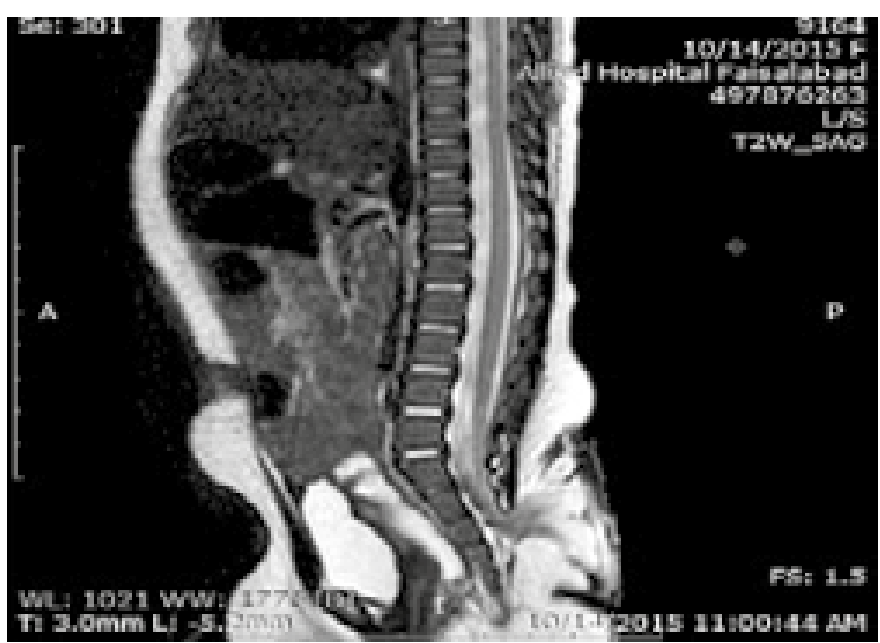

B

Figure-6. Myelomeningocele in a 1 day old female infant.

MRI T1W (a) \& T2W (b) sagittal images showing sacral myelomeningocele, tethered cord \& associated syrinx formation.

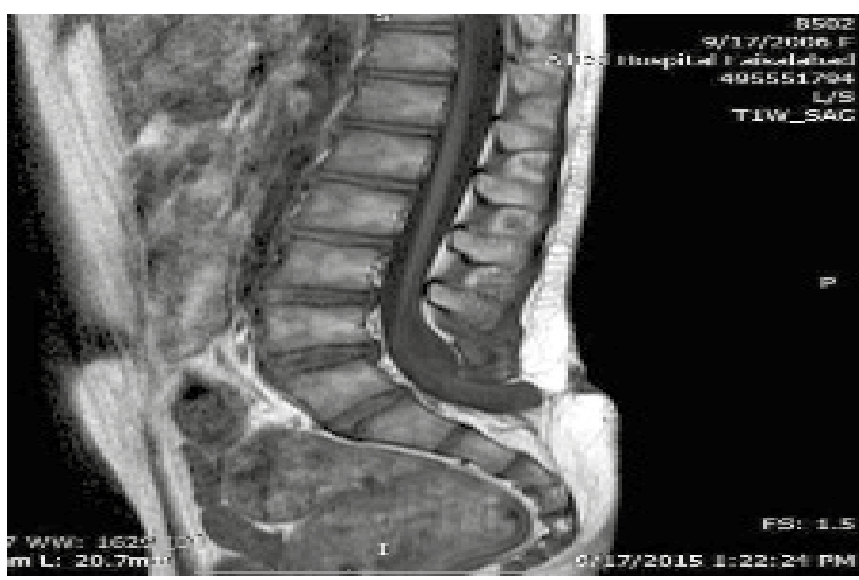

A

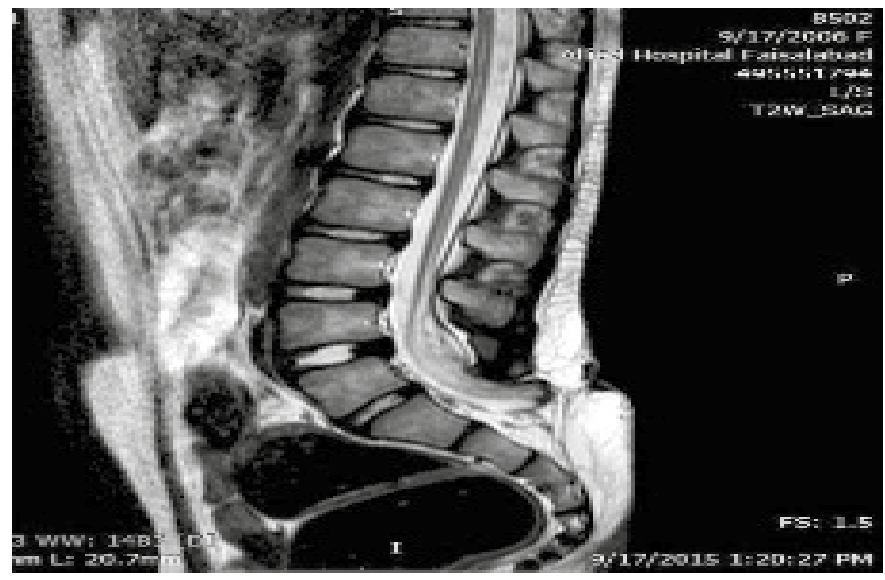

$\mathbf{B}$

Figure-7. Myelocele / myeloschisis in a 9 year old girl with urinary symptoms since birth. MRI T1W \& T2W sagittal images $(a, b)$ showing myelocele, tethered cord \& associated syrinx formation. 

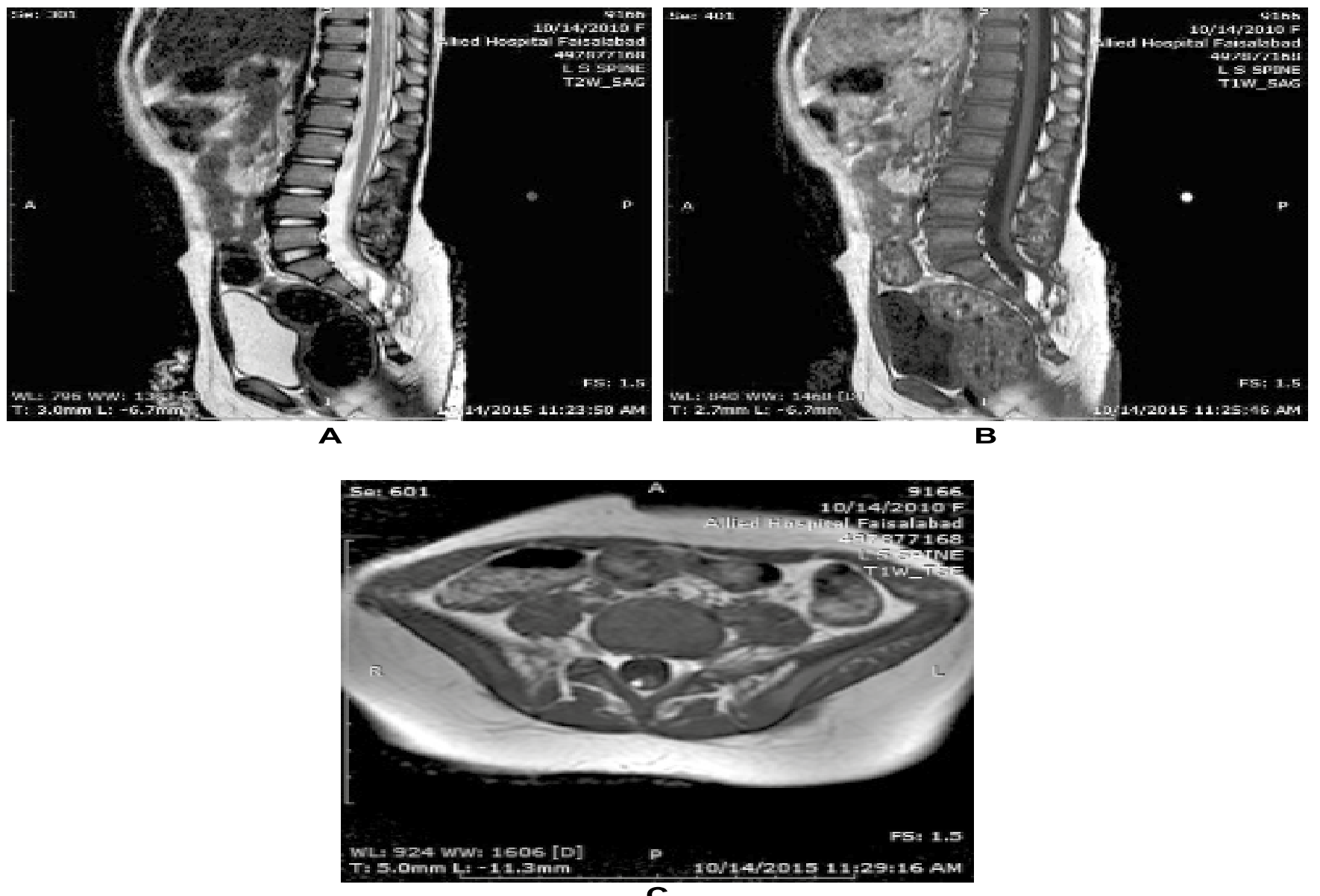

Figure-8. Tethered cord with intradural lipoma in a 5 year old girl with urinary symptoms.

MRI T2W sagittal (a) \& T1W sagittal (b) and T1W axial (c) showing low lying thick filum terminales with associated intradural lipoma as hyperintense T1W signal intensity mass.

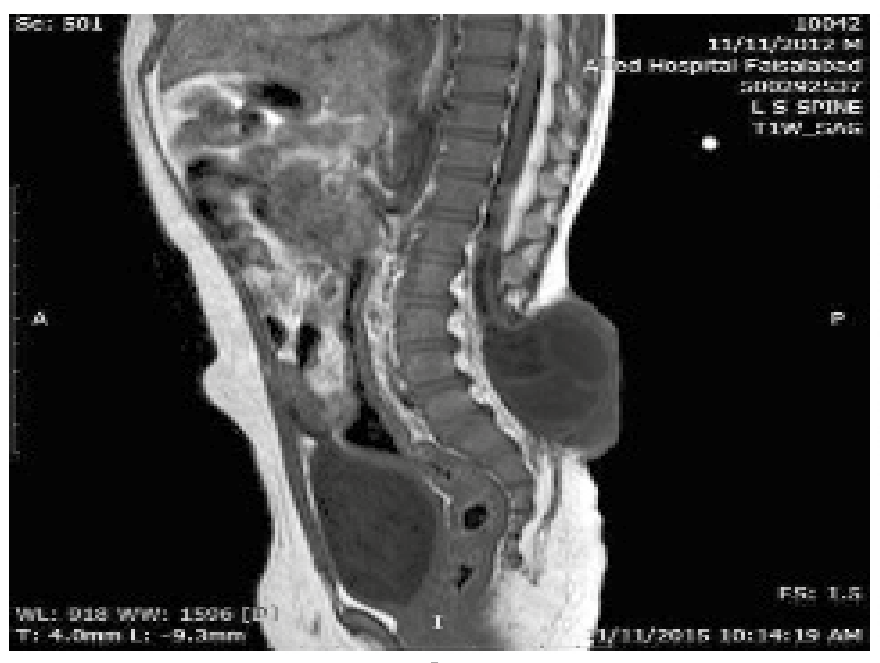

A

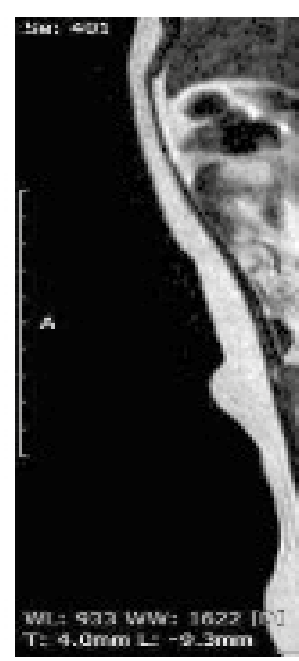

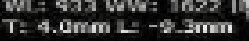

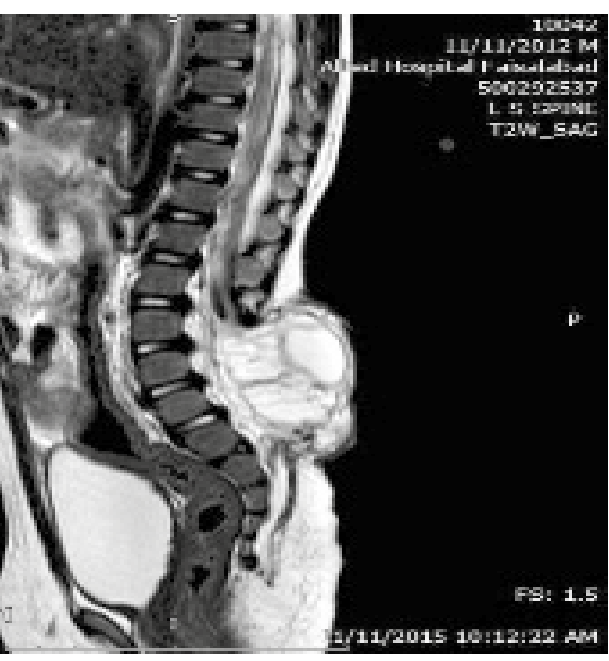

B

Figure-9. Complex meningomyelocele in a 3 years old male baby who presented with lower back swelling since birth along with urinary symptoms \& weakness lower limb.

MRI T1W (a) \& T2W (b) sagittal images showing complex meningomyelocele appreciated as multiseptated cystic CSF containing lesion protruding through deficient posterior elements at the lumbosacral region. 


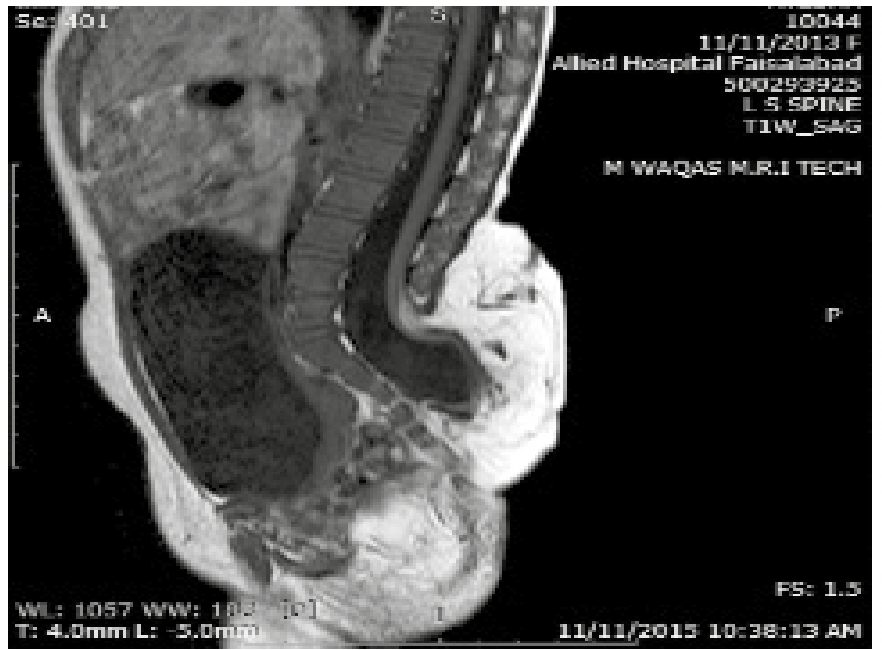

A

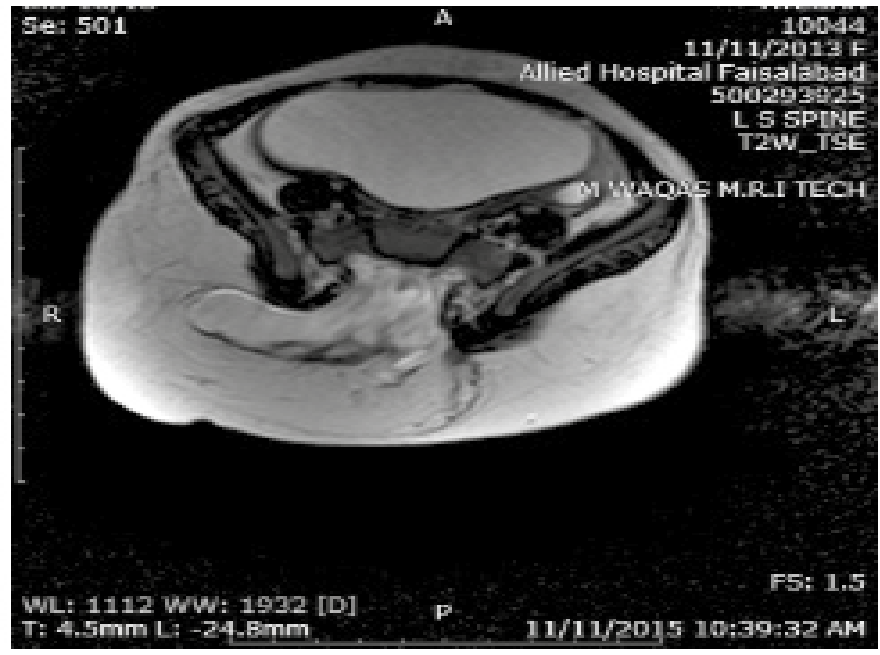

B

Figure-10. Myelomeningocele in a 2 years old female baby with swelling lower back and weakness since birth.

MRI T1W sagittal (a) \& T2W axial (b) images of the lumbosacral spine showing myelomeningocele with associated subcutaneous lipoma.

We can classify a spina bifida by many ways. ${ }^{20}$ One method is according to extent or the defect and is as:

1) Spina bifida aperta: defect can be open / closed as,

a) Spina bifida aperta without cystica (meni ngocoele)

b) Spina bifida cystica (myelomeningocoele)

c) Myeloschisis (exposure of the spinal cord directly to the external environment, meningeal / skin covering not present)

d) Rachischisis

2) Spina bifida occulta: the most benign type.

We can also classify them by another method that is according to position as:

I. Anterior (ventral) or

II. Posterior (dorsal). Dorsal spina bifida constitutes vast majority of these cases.

Another subclassification of the spina bifida is as under:

a) Open: (80-90\%) especially if detected during intra uterine life $)^{21}$

1) Myeloschisis

2) Myelomeningocoele ( in most cases open, associated with Chiari II malformation)

b) Closed: according to presence of the covering skin.
1) Meningocoele (could be open)

2) Lipomyelomeningocoele

Spinal dysraphism is a defect that is present at birth, causing various types of secondary impairments, including joint deformities. ${ }^{11}$

Symptoms incorporate incontinence of the bladder \& bowel, pain involving back and legs, scoliosis, weakness of the lower extremity, a limp, atrophy of a limb, spasticity and vaguely defined lower extremity changes as well as foot abnormalities (e.g. pescavus) $)^{12}$

In our study, presenting complaint was swelling in the lumbosacral region among most of the patients.

A total of 20 cases (09 males and 11 females) with age range from $1^{\text {st }}$ day of life to 10 years were evaluated for dysraphic states.

Dermal sinus tract was found in $10 \%$ of the cases in our study while study conducted by Rossi et al shows its incidence as $11.3 \%^{13}$ and $17.6 \%$ in study conducted by Nishtar T et al. ${ }^{14}$ In our study 7 patients out of the total 17 patients were infants, all of whom presented with soft tissue swelling lumbosacral region and were diagnosed as having spinal dysraphism by performing MRI 
of the lumbosacral spine, which showed these infants to be suffering from a spectrum of spinal dysraphic state, ranging from spina bifida to split cord syndrome (diastematomyelia). ${ }^{16}$ The incidence of diastematomyelia in our study was $10 \%$ while study done by McComb et al shows its incidence to be $20-40 \%$ of the case ${ }^{15}$ and study done by Nishtar T et all to be $41.1 \% .^{14}$

$\mathrm{MRI}$ is a noninvasive investigation and radiation is not involved, rendering it to be the investigation of the choice for the detection of occult spinal dysraphism. By MRI, we can better identify the intraspinal extension of a lipoma and the exact localization of the conus medullaris, both of these affect surgical management. Moreover, $\mathrm{MRI}$ is very important for pre-empting the use of myelography, which is not completely risk free.

Despite that, MRI requires sedation in the infants and the babies, ${ }^{17}$ which was also provided in around $70 \%$ of our patients.

With advances in surgical and medical management, long term care of spinal dysraphism cases has turned into an imperative issue. $\mathrm{MRI}$ is now considered as the best radiologic examination. Plain radiographs and ultrasound are not much helpful, and there are high chances of morbidity with invasive investigations. As MRI is a safe and risk free procedure with its excellent diagnostic value, it is considered as the first line investigation for the diagnosis spinal dysraphic states. ${ }^{18,19}$

\section{CONCLUSION}

$\mathrm{MRI}$ is the considered as the best method of investigation for the detection of occult spinal dysraphism. Diagnosis made at right time by MRI, improves surgical \& medical outcome as well as better \& long term care of patients with spinal dysraphism. Majority of patients in the current study had tethered cord (75\%), myelomeningocele (20\%), myelocele (10\%), lipomyelocele (10\%) Dermal sinus tract (10\%) \& diastematomyelia (10\%) followed by associated spinal lipomas (5\%), caudal agenesis (5\%) \& anterior meningocele (5\%)

Copyright@ 20 Feb, 2017.

\section{REFERENCES}

1. Thompson D. Spinal dysraphic anomalies; classification, presentation and management. Paediatrics and Child Health 2014.

2. Thompson D. Spinal dysraphic anomalies; classification, presentation and management. Paediatrics and Child Health. Volume 20, Issue 9, Pages 397-403, September 2010.

3. FrimD.Spinaldysraphism.Chapter:http://www.landesbioscience.com/vademecum/Frim_9781570597503.pdf ISBN 978-1-57059-643-8.

4. Warder DE. Teethard cord and occult spinal dysraphism. Neurosurg Focus 2001; 15:10:e1.

5. Tortori-DonatiP, RossiA, BiancheriR, CamaA. Magnetic resonance imaging of spinaldysraphism. TopMagnResonlmaging2001; 12:375-409.

6. Anderson FM. Occult spinaldysraphisms: diagnosis and management. JP edi-atr 1968; 73:163-178.

7. Sury MR, Hatch DJ, Deeley T et al (1999) Development of a nurse-led sedation service for paediatric magnetic resonance imaging. Lancet 56:388-391.

8. Sury MR, Harker $\mathrm{H}$, Begent $\mathrm{J}$ et al (2005) The management of infants and children for painless imaging. ClinRadiol 60:731-741 (ISSN: 2393 - 9117).

9. Hughes JA, De Bruyn R, Patel K et al (2003) Three-dimensional sonographic evaluation of the infant spine: preliminary findings. J Clin Ultrasound 31:9-20 [PubMed].

10. Makary R, Wolfson D, Dasilva V, Mohammadi A, Shuja $S$. Intramedullary mature teratoma of the cervical spinal cord at $\mathrm{C} 1-2$ associated with occult spinal dysraphism in an adult. Case report and review of the literature. J Neurosurg Spine.

11. D'Addario V, Rossi AC, Pinto V, Pintucci A, Di Cagno L. Comparison of six sonographic signs in the prenatal diagnosis of spina bifida. J Perinat Med. 2008; 36(4): 330-34.

12. Musson RE, Warren DJ, Bickle I, Connolly DJ, Griffiths PD. Imaging in childhood scoliosis: a pictorial review. Postgrad Med J 2010; 86: 419-27.

13. RossiA, CamaA, Piatelli G, Ravegnani M, Biancheri R, Donati PT. Spinal Dysraphism: Mr Imaging Rationale. J. Neuroradiol 2004; 31(1): 3-24.

14. Nishtar $T$, Elahi $A$, Iqbal $N$. To determine the frequency of accuracy of mri in diagnosis of rare disorder of spinaldysraphism. J. Med. Sci. (Peshawar, Print) October 2011, Vol. 19, No. 4: 195-199. 
15. McComb JG. Spinal and cranial neural tube defects. Semin Pediatr Neurol. Sep 1997; 4(3): 156-66.

16. Guggisberg D, Rabia HS, Viney C, Bodemer C, Brunelle $\mathrm{F}$, Zerah $\mathrm{M}$ et al. Skin markers of occult spinal dysraphism in children, A Review of 54 Cases. Arch Dermatol. 2004; 140:1109-15.

17. Filippidis AS, Kalani MY, Theodore N, Rekate HL. Spinal cord traction, vascular compromise, hypoxia, and metabolic derangements in the pathophysiology of tethered cord syndrome. Neurosurg Focus. $2010 \mathrm{Jul}$; 29(1): E9.

18. Ross M, Brewer K, Wright V, Agur A. Closed Neural
Tube Defects: Neurologic, Orthopedic, and Gait Outcomes. Pediatr Phys Ther 2007; 19: 288-95.

19. Patrick T. Tracy, William C. Hanigan. Spinal Dysraphism- Use of Magnetic Resonance Imaging in Evaluation. Clin Pediatr 1990; 29: 228-33.

20. Dr Ayush Goel and Dr Yuranga Weerakkody $\square$ et al. Spina bifida. Radiopaedia.org.

21. Ghi T, Pilu G, Falco P et-al. Prenatal diagnosis of open and closed spina bifida. Ultrasound Obstet Gynecol. 2006; 28 (7): 899-903. doi:10.1002/uog.3865 - Pubmed citation.

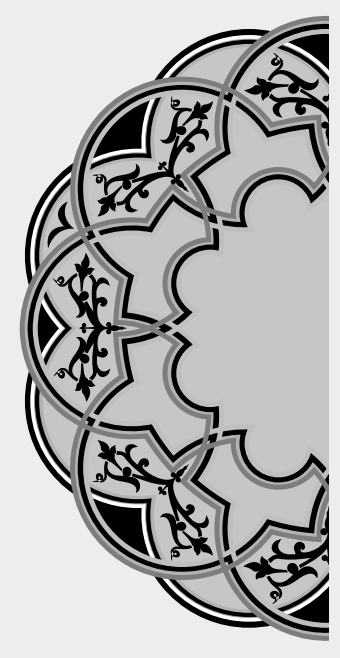

\title{
"The greatest mistake you can make in life is to continually be afraid, that you will make one."
}

\author{
Elbert Hubbard
}

\section{AUTHORSHIP AND CONTRIBUTION DECLARATION}

\begin{tabular}{|c|l|l|}
\hline Sr. \# & \multicolumn{1}{|c|}{ Author-s Full Name } & \multicolumn{1}{|c|}{ Contribution to the paper } \\
\hline 1 & Dr. Bushra Ujala & Author \\
2 & Dr. Saeeda Bano & Author \\
3 & Dr. Asma Mehreen & Co-author \\
4 & Dr. Hassan Bukhari & Co-author
\end{tabular}

